\title{
Entre Nietzsche y Foucault: la historia y la crítica como ética
}

\author{
Emmanuel Guerrero Trejo \\ Universidad de Guanajuato \\ groemmanuel23@gmail.com
}

El concepto de «historia crítica» en Nietzsche se refiere a una crítica contra la forma en la que se concibe la historia y la forma en la que ésta afecta y gobierna negativamente la vida de las personas. La crítica de la que hablamos es de ese hecho en el que se juzga el pasado, que se presenta como el único verdadero y que, como ya dijimos, afecta a la vida. De esta forma, el hombre o la cultura que tenga esta visión se dará cuenta de que su vida es el resultado de muerte, destrucción e injusticias, $\mathrm{y}$ no de un mandato divino. $\mathrm{Y}$ es por eso que la vida que se generará a partir del juicio sobre el pasado será más saludable.

Esta crítica, que consiste en poner en tela de juicio aquello que se presente como verdadero, es la misma crítica que nos expone Michel Foucault en su texto ¿Qué es la crítica? Para este autor, la crítica es poner en tela de juicio ciertos discursos que nos gobiernan. De esta forma no seremos gobernados por esos saberes sino por otros que forman otro tipo de sujeto $\mathrm{u}$ otra ética diferente. Ética entendida, precisamente, como la construcción de una forma de ser específica a partir de unas relaciones específicas de saber y de poder. 
Por eso, en este texto mostraremos que podemos entender la visión de la historia crítica como la formación de una ética. Decimos esto porque esta historia juzga unas verdades en el pasado que se presentan como las únicas. Porque juzgando esas verdades, dice Foucault, dejas de ser gobernado por ellas y se despliegan otras que acarrearán una nueva ética.

Para poder llegar al objetivo que hemos planteado, a saber: que la historia crítica genera una ética, primero mostraremos, a partir del pensamiento de Nietzsche, la forma en la que la historia afecta la vida y cómo se genera la noción de historia crítica. En segundo lugar, mostraremos lo que Foucault entiende por «crítica» y por «ética». Así mostraremos que mediante la crítica podemos emparentar historia y ética.

Primeros esbozos de la crítica y la historia en Nietzsche

Para Nietzsche todo problema es un problema axiológico, es decir: todo problema es un problema de valor. ¿Pero qué significa «valor» para Nietzsche? Se trata de las diferentes maneras en las que se concibe la realidad y se valoriza el mundo. Estas valoraciones siempre se encuentran en una lucha por el poder, por imponerse como las únicas. Por eso decimos, junto con Nietzsche, que el mundo es voluntad de poder (Nietzsche, 1972). Por eso mismo no se habla de la verdad metafísica y última de todas las cosas, sino de diferentes valorizaciones que se quieren imponer.

Pero ¿a qué se está refiriendo aquí con voluntad de poder? Una de las ideas básicas en el pensamiento de Nietzsche es sin duda la del hombre como creador del valor. Desde la perspectiva de este autor, el hombre, para poder sobrevivir y para poder dar sentido a su vida, se encargó de evaluar todo aquello que le rodeaba, se encargó de ponerle un valor a las 
cosas. Evaluar es crear, el hombre es creador. Y ésa es precisamente la voluntad de poder: afirmar lo que se juzga, se evalúa y se crea, o lo que es lo mismo, afirmarse a sí mismo.

El problema se presenta cuando se ejerce esa actitud evaluadora hacia un sentido trascendente, es decir: cuando se busca la verdad última e inamovible que devenga como un sustento seguro desde el cual poder evaluar todo. Un ejemplo de ello es el paradigma platónico, pues al no soportar la contingencia y el devenir del mundo, postula otro suprasensible, inamovible, eterno y universal a partir del cual sostenerse para explicar la realidad (Nietzsche, 2001).

Es de esta misma idea de la que, en gran medida, el cristianismo se sostuvo. Éste, al negarse a enfrentar todo el devenir y el sinsentido de la realidad concreta, optó por un soporte universal y eterno, optó por el conocimiento de Dios para explicarlo todo. Dios es la belleza, la verdad y, sobre todo, Dios es la bondad. Cuando se hace de Dios la bondad, se fabrica una justificación para que todo tenga que entrar en el saco de este soporte trascendente, pues al final de cuentas, lo bueno es lo deseable. Para las perspectivas metafísicas de este tipo, el bien es el fin al que aspira todo hombre. Así, el cristianismo gana la lucha por el poder de crear los valores (Colomer, 2001).

La crítica de Nietzsche contra todo eso consiste en mostrar que la honestidad, la compasión, la justicia, la intemperancia y todos los valores cristianos y metafísicos son producto, no de una verdad última e inmutable, sino de guerra, destrucción, injusticia y suciedad. Nietzsche señala en su texto La genealogía de la moral que los valores que tenemos entendidos por buenos, gracias a la contaminación de la visión platónico-cristiana del mudo, son producto de una lucha por el poder, de una lucha por imponer los fundamentos desde los cuales se evaluará la existencia, como hemos dicho antes (2005). 
Esta lucha consiste, por un lado, en la condición de los amos, los que crean los valores y los imponen a base de sometimiento, muerte y destrucción del otro. Y por otro, los esclavos o los judíos, podemos decir también los cristianos, los que usan la compasión y el perdón con el fin de imponer su supuesta verdad (2005). Entonces, es así como se imponen los conocimientos, los valores, lo bueno y lo malo: por medio de una lucha de poder.

La crítica de Nietzsche consiste entonces en el rastreo de la emergencia inmanente de las verdades eternizadas, para mostrar que éstas no tienen un origen glorioso, son producto de luchas y guerras. Pero unas luchas y unas guerras sometidas al devenir inmanente de la historia. Habrá que destruir estas supuestas verdades y enfrentar el sinsentido del mundo para poder crear nuestros propios valores. Pues estas verdades no son eternas, son artificios, construcciones históricas, por tanto, son susceptibles de destrucción. Una destrucción que permitirá al hombre asumir su rol como creador.

Bajo estos supuestos teóricos que hemos expuesto, Nietzsche se encargó de analizar en su obra Sobre la utilidad y el perjuicio de la historia para la vida, las formas en las que la historia construye vidas, es decir, Nietzsche se encargó de analizar las diferentes maneras en la que los hombres, ciudades y culturas construyen su vida a partir de las visiones que tienen de su pasado.

En esta obra, el autor se opuso rotundamente a aquella tendencia que tienen los historiadores de hacer de la historia una ciencia rigurosa al estilo de la física o la química. Este tipo de historia, según Nietzsche, es un atentado contra la vida, porque hace que los hombres entreguen todo por ese saber abstracto del pasado olvidándose totalmente de la vida en el presente. Así los hombres, al ser aduladores 
del desarrollo completo y universal de la historia, olvidan, insistimos, por completo lo que sucede con su vida actual (Nietzsche, 1999).

Contra esta ciencia de la historia que hace del pasado el sepulturero del presente, es necesario, dice Nietzsche, conocer esa capacidad que tienen los hombres y los pueblos de cambiar su vida y de transformar su presente. A esta capacidad de transformación del hombre el autor la llama «fuerza plástica».

Para determinar este grado, y, sobre este fundamento, los límites en los que el pasado ha de olvidarse para no convertirse en sepulturero del presente, se tendría que conocer exactamente el grado de fuerza plática de un hombre, de un pueblo o de una cultura; quiero decir: esa fuerza para crecer por sí misma, ese poder de transformar y asimilar lo pasado y extraño, de sanar las heridas, de reemplazar lo perdido, de regenerar las formas restituidas (Nietzsche, 1999: 43).

Tan necesario para la salud de un hombre es el olvido, como lo es también el recuerdo de su pasado; este último es necesario porque el hombre no puede dejar de ser histórico, es decir, no puede dejar de recordar. Pero cuando se hace evidente esa necesidad, los historiadores hacen de ese recuerdo una ciencia dura que sepulta el presente. Es aquí donde esta fuerza plástica es necesaria para hacer que sus recuerdos afecten positivamente a la vida de hoy; pero si negamos, junto a Nietzsche, aquella noción de «historia», entonces podemos hacer de cualquier momento particular de la historia una herramienta para sanar la vida del presente (Nietzsche, 1999). De esta manera el autor nos presenta tres formas en las que la 
historia afecta a la vida. La primera es la que llama «historia monumental», la segunda es la «historia anticuaria»y la tercera es la «historia crítica».

Con la historia monumental se trata de hacer de los momentos históricos una motivación para soportar el presente, es decir: si alguna vez fueron posibles actos heroicos e increíbles que hicieron inmortales a quienes los realizaron, entonces es posible que vuelvan a ocurrir semejantes actos. Por lo mismo, los que utilizan la historia de manera monumental voltean al pasado para tomar un respiro y realizar sus propios actos increíbles (Nietzsche, 1999).

El problema con este tipo de historia es que todos los momentos individuales e insignificantes de la vida presente se despojan de su valor. La existencia de estos pequeños momentos es casi nula en comparación con esas grandezas del pasado que se quieren repetir. Además, para traer al presente aquellos momentos increíbles, los tiempos actuales tendrían que tener las mismas características que tuvieron los tiempos en los que se efectuaron dichos actos, lo cual no es posible.

Mientras que la historia anticuaria es la que recuerda, conserva y venera. La persona anticuaria voltea a la historia de su pueblo y agradece por tener el supuestamente maravilloso presente que tiene. Esta persona, llena de amor, con mucho esfuerzo lucha para conservar las tradiciones que a lo largo del tiempo han formado y preservado la vida de su familia y de su pueblo. Para ellos es impensable que lo fresco de las novedades jóvenes manche las sagradas costumbres de los viejos (Nietzsche, 1999).

No obstante, cuando se acepta que este tipo de historia influye en la vida, se acepta que las novedades importantes y positivas se desechen como el peor de los desperdicios, sin importar que impliquen una vida más saludable. Otro pro- 
blema con esta manera de ver la historia es que, si la vida es el resultado de ese pasado podrido y supuestamente bueno, entonces dicha vida es el resultado también de las guerras, muerte y desgracias que ese pasado tuvo en su momento para hacer posibles aquellas buenas costumbres; contra estas dos maneras en las que la historia afecta a la vida, Nietzsche propone la historia crítica. En ésta lo que permea es el juicio sobre el pasado, es decir, el juicio que se puede ejercer sobre todo momento de la historia. Según Nietzsche, aquí no juzga la verdad ni la bondad, sino la propia vida ${ }^{1}$, entonces, la vida es la que gana.

Es menester que el hombre, para poder vivir, tenga la fuerza de destruir y liberarse del pasado, así como que pueda emplear dicha fuerza de vez en cuando. Esto lo consigue llevando el pasado a juicio, instruyendo en su caso de manera dolorosa, para, finalmente, condenarlo, ya que todo pasado es digno de ser condenado, pues así acontece en las cosas del hombre, siempre envueltas en las fuerzas y debilidades humanas. Pero no es aquí la justicia la que lleva las cosas humanas a juicio; y aún menos la clemencia la que pronuncia el veredicto. Es únicamente la vida quien aquí se expresa, ese poder oscuro e

1 Hasta ahora hemos usado indiscriminadamente el concepto de «vida». Dentro del pensamiento de Nietzsche este concepto adquiere muchas connotaciones que no desarrollaremos aquí por falta de espacio. Por ejemplo, en El nacimiento de la tragedia, se alcanza a asomar una aproximación a dicho concepto al afirmar que lo real no son sólo los objetos físicos y cognoscibles de la ciencia dura, o los conceptos inteligibles del entendimiento, sino que lo real tiene que ver también con la muerte, la enfermedad, la embriaguez o la diversión. La vida es algo más que el conocimiento, es también el devenir de lo inmanente, lo accidental, lo concreto. En términos generales, la vida, en esta obra, se presenta como el acompañamiento de lo apolíneo con lo dionisiaco. Este tema, como lo dijimos, no es el que nos interesa por el momento, sino mostrar la crítica que Nietzsche hace a las nociones metafísicas de la historia y que, más adelante, podremos caracterizar como una ética (Nietzsche, 2010: 150). 
incitante, ese poder que con insaciable afán se desea a sí mismo (Nietzsche, 1999: 65).

Con la historia crítica se juzga el pasado impuesto como verdadero y que afecta negativamente la salud de la vida. Pero aquí la que juzga y valora es la vida misma, con el fin de mantener su salud. No es Dios ni las pretendidas buenas costumbres, sino únicamente la vida la que sale ganando en esta concepción de la historia.

Podemos notar que esta visión de la historia es presentada como una crítica al puro estilo nietzscheano, es decir: se destruye todo discurso que se presente como el único verdadero. En este caso, se están destruyendo las visiones metafísicas de la historia y que, por lo mismo, asesinan a la vida. Esta misma noción de «crítica», guardando las debidas proporciones y diferencias, es la que, desde cierta perspectiva, podemos ver en el pensamiento de Foucault pues, para él, la crítica es una forma de resistencia ante el poder y el gobierno que atraviesan las prácticas de los sujetos. Tanto para Foucault como para Nietzsche, la crítica es totalmente práctica: va más allá del mero discernimiento de lo verdadero y de lo falso, tiene que ver con las conductas que se adquieren, tiene que ver con la ética.

\section{Crítica: saber, poder y ética en Michel Foucault}

Si en Nietzsche la crítica trata de juzgar las supuestas verdades eternas, en Foucault se trata de poner en evidencia las relaciones de poder en las que caen esas supuestas verdades y las sujeciones de individuos que éstas causan. Como podemos notar, la crítica no se centra únicamente en términos de conocimiento. La crítica, desde el punto de vista de Foucault 
y de Nietzsche, se centra en la destrucción de las universalidades que gobiernan la vida.

Por ejemplo, piénsese en algunos acontecimientos peculiares presentes en la Edad Media y en el Renacimiento: la cuestión de gobernar a los hombres mediante la pastoral cristiana, las formas de gobierno de una ciudad, la escuela, etcétera; lo que llamamos, junto a Foucault, «el arte de gobernar a los hombres» (1999a: 333). Y es este gobierno de los hombres al que se tiene que atacar. Sin embargo, la crítica no se trata de contraponer al arte de gobernar un arte de no ser absolutamente gobernado. Foucault no pretende dar una receta para salir del poder. El problema de la crítica se centra en aquella posición del arte de no ser de cierta forma gobernado, es decir, «cómo no ser gobernado de esa forma, por ése, en nombre de esos principios, en vista de tales objetivos y por medio de tales procedimientos, no de esa forma, no para ellos, no por ellos» (1999a: 335).

El problema de la crítica se centra en el gobierno, ya lo hemos dicho, no un gobierno por fuera de los propios individuos, sino dentro de ellos. Pues los individuos son gobernados, mediados y sometidos por los saberes que forman parte de su existencia, digámoslo así. Esos saberes siempre son acompañados por relaciones de poder y, dentro de éstas, los individuos se construyen una forma de ser. La crítica está dirigida hacia las relaciones de saber, que traen ya consigo relaciones de poder, a partir de las cuales los sujetos, los individuos, se forman.

[...] la crítica es el movimiento por el cual el sujeto se atribuye el derecho de interrogar a la verdad acerca de sus efectos de poder y al poder acerca de sus discursos de verdad; la crítica será el arte de la incertidumbre 
voluntaria, de la indocilidad reflexiva. La crítica tendrá esencialmente como función la desujeción en el juego de lo que se podría denominar, con una palabra, la política de la verdad (1999a: 339).

Insistimos en decir que la crítica es ese hecho de interrogar a los saberes, a las verdades eternas si me lo permiten, que llevan consigo un control sobre los individuos, un poder, y una actitud. Se trata de interrogar, como ya lo hizo Nietzsche, lo que aquí Foucault llama la política de la verdad. Y la política de la verdad no es más que un conjunto de ejercicios del poder acompañados siempre de unas relaciones de saber, pero, ¿qué quieren decir estos últimos conceptos?

Las relaciones de saber son todo aquello que delimita lo que puede entenderse como verdadero y como falso. Son los límites de lo conocido y lo desconocido. El saber es ese espacio en el que se establecen los objetos que pueden ser estudiados y los que no, los enunciados que dicen verdad y los que no lo hacen, los sujetos que pueden expresar esos enunciados y los sujetos que funcionan como objetos. No es el descubrimiento de las cosas mismas, es la construcción y la delimitación, digamos, artificial ${ }^{2}$, de la verdad (Foucault, 1999b: 364).

Mientras que las relaciones de poder son acciones sobre otras acciones, el poder es un ejercicio para la dirección de

2 Cuando decimos que la verdad se construye artificialmente, nos referimos a que lo que interesa aquí es el estudio de los campos específicos en los que cada uno establece alguna o algunas verdades diferentes que no se cuestionan. Pero tanto para nosotros, como para Foucault, éstas no son verdades en sí mismas, sino que cambian dependiendo del campo que las establezca. En términos generales, no se busca cuál es la verdadera verdad, sino el estudio de las diferentes construcciones de la verdad en ciertos campos o ciertos momentos de la historia. 
las conductas. No es una entidad absoluta que mantiene a los sujetos totalmente reprimidos, al contrario, los hace útiles, dirige sus conductas para que realicen determinadas acciones o para que se comporten de determinada manera. En términos generales, el poder construye a los sujetos desde los cuales aparecerán las relaciones de saber que, a su vez, desplegarán nuevas relaciones de poder. Saber y poder se encuentran siempre íntimamente relacionados (Foucault, 1998). Estas relaciones son las condiciones de posibilidad que permiten la existencia de los sujetos.

Las relaciones de saber y de poder imperan en todo momento y en todos los aspectos de la vida de los sujetos. Los individuos están siempre atravesados por el poder, siempre están asumiendo normas de conducta, siempre están siendo educados y normalizados de acuerdo con la verdad establecida y a lo permitido en su campo. No es posible estar por fuera de estas relaciones porque siempre que se liberan de unas caen en otras diferentes. Y el sujeto no es una entidad fundante sino un resultado de todo un abanico de relaciones.

La crítica entonces es una especie de resistencia ante esa política de la verdad. Es el cambiar de sentido el ejercicio del poder para no ser gobernado de una manera determinada. Si bien es cierto que no es posible salir del poder, la crítica representará una resistencia dentro del mismo: la crítica no consiste en salir del gobierno y del poder, sólo en cambiarlo de sentido. Consiste en la adquisición de otras conductas a partir del mismo poder y eso mismo es la ética. La crítica se asoma aquí como el ejercicio de una ética.

Esta última tiene que ver con los modos en los que los sujetos, por sí mismos, asumen pues las conductas: tiene que ver con la manera en la que un individuo debe dar forma a tal o cual parte de sí mismo para asumir determinada ma- 
nera de comportarse. Tiene que ver también con la relación que el sujeto establece con esas normas para aceptarlas o dejarlas de lado (no por imposición, sino por sí mismo). Y con lo que se modifica en su interior al asumir dichas conductas. Como vemos, la ética o la moral no se reducen a los códigos o normas, es todo un trabajo de un sujeto por sí mismo sobre su existencia. Así se construye la forma de ser, así se forja el carácter (Foucault, 2009).

En suma, para que se califique de «moral» una acción no debe reducirse a un acto o a una serie de actos conformes a una regla, una ley y un valor. Cierto que toda acción moral implica una relación con la realidad en donde se lleva a cabo y una relación con el código al que se refiere, pero también implica una determinada relación consigo mismo; ésta no es simplemente «conciencia de sí» sino constitución de sí como «sujeto moral», en la que el individuo circunscribe la parte de sí mismo que constituye el objeto de esta práctica moral, define su posición en relación con el precepto que sigue, se fija un determinado modo de ser que valdrá como cumplimiento moral de sí mismo, y para ello actúa sobre sí mismo, busca conocerse, se controla, se prueba, se perfecciona, se transforma (Foucault, 2009: 29).

En resumen, la ética es el modo en el que el sujeto asume o rechaza determinadas conductas que se le presentan. Esas formas en las que realiza esa acción tienen que ver menos con los propios códigos y normas de los que emanan esas conductas y más con el modo en el que el sujeto las asume por sí mismo, con el modo en el que él mismo se toma por objeto, se relaciona consigo mismo y se modifica. Es por eso por lo que decimos 
que la ética depende de las relaciones de poder, en tanto que hay una dirección de la conducta (la del propio sujeto sobre sí mismo) y de las relaciones de saber, en tanto que el ejercicio de la ética está dentro de un espacio de reglas y normas que se le presentan como verdaderas al sujeto.

Dado que la ética es el ejercicio del poder sobre un sujeto por sí mismo, ésta es una crítica y se hace para liberarse, para dejar de lado cierto tipo de modificación del poder, por tanto, puede hablarse de un tipo de libertad. No obstante, cuando uno deja de lado determinado ejercicio del poder, ejercita otro, o cae en otro tipo de ejercicio del mismo, por eso la libertad no es absoluta, es una libertad construida. Consiste, podríamos decir, en ser parcialmente gobernado, en dejar de ser gobernado de una forma específica, en elegir la forma en la que uno va a ser atravesado por el poder. La libertad no consiste en salir del poder, sino en modificarlo, ejercitarlo de otra manera, eso es la ética y así se relaciona con la crítica.

Por tanto, podemos colocar a la crítica, a la ética y a la libertad en un mismo plano si nos basamos en el pensamiento de Foucault. También alcanzamos a notar que la historia crítica puede colocarse en ese mismo plano. La historia afecta a la vida de determinadas maneras, es decir, la historia genera actitudes, conductas y subjetividades. La historia crítica mata aquellas visiones de la historia que enferman la vida, por eso puede considerarse una crítica y una ética en la que se practica la libertad.

\section{Historia, crítica y ética}

Para concluir este escrito, daremos un breve pero significativo repaso de lo que hemos dicho hasta ahora. Comenzamos exponiendo los rasgos más importantes del pensamiento de 
Nietzsche. A partir de esta exposición dijimos que la crítica en este pensador consiste en juzgar las verdades universales que se presentan como las únicas verdaderas, como los valores cristianos. El juicio contra estas verdades se expresa cuando, a partir del análisis histórico, se demuestra que dichas verdades son el resultado de una lucha de poder que ha consistido, en cada uno de los momentos de su historia, en asesinatos, destrucción y en todo tipo de injusticias. Esta crítica hace posible que el hombre asuma su rol de creador y de valorador de la existencia.

Con estos presupuestos el autor propone su concepto de «historia crítica». Tal concepto expresa el juicio que un hombre o una cultura puede realizar contra su pasado. Un pasado que afecta a la vida negativamente, que mata al presente y que acarrea miseria a dichas vidas. Con la historia crítica es posible darle un lugar a cada uno de los pequeños momentos de la historia de un hombre o de una cultura; incluso a los momentos de injusticias y de pérdidas. De esta manera la historia que afectará a la vida será una historia cargada de sanidad, puesto que le otorga a cada uno de sus momentos, por más insignificantes que sean, el lugar que merecen.

La crítica de Nietzsche es similar a la de Foucault. La noción de «crítica» en el pensamiento de este último autor, consiste en juzgar ciertas verdades que nos gobiernan y que dirigen nuestras acciones pero que hacen de nuestra vida una miseria. Contra esto, Foucault propone ser gobernados por otras verdades que nos favorezcan. Por eso mismo podemos entender que la crítica es una ética, porque la ética es eso mismo, a saber, es el resultado de relaciones de saber y de poder, pero esta vez ejercidas sobre el sujeto por el sujeto mismo, de tal manera que ese ejercicio lo haga libre. 
Pero cuando realiza tal ejercicio de la libertad, cae en otro tipo de relaciones que también dirigirán su conducta. No obstante, aunque al realizar el ejercicio ético de la crítica, también caemos en algún gobierno de algunas verdades, dichas verdades serán favorables para nuestra vida. Lo importante es no ser de cierta forma gobernado, sino de una forma no habitual y no grotesca.

Con Nietzsche podemos saber cuáles verdades criticar: hay que matar las verdades históricas que hacen que quitemos la mirada del presente, las verdades que matan la vida y a las personas. Con Foucault podemos hacer de esa crítica una ética de la cotidianidad. Podemos hacer de esa crítica una relación de poder ejercida sobre nosotros mismos para no ser gobernados por las visiones históricas asesinas, sino ser gobernados por la verdad de la crítica y practicar una libertad.

\section{Bibliografía}

Colomer, E. (2001). El pensamiento alemán, de Kant a Heidegger. España: Herder.

Foucault, M. (2009). Historia de la sexualidad vol. II: El uso de los placeres. México: Siglo XXI.

Foucault, M. (1999a). Sobre la ilustración, entre filosofía y literatura. España: Paidós.

Foucault, M. (1999b). Obras esenciales vol. II: Estética, ética y hermenéutica. España: Paidós.

Foucault, M. (1998). El sujeto y el poder. Revista Mexicana de Sociología, 3(50).

Nietzsche, F. (2010). El nacimiento de la tragedia o helenismo y pesimismo. España: Gredos.

Nietzsche, F. (2005). La genealogía de la moral. España: Alianza. 
Nietzsche, F. (2001). Humano, demasiado humano. Un libro para espíritus libres, vol. I. España: Akal.

Nietzsche, F. (1999). Sobre la utilidad y el perjuicio de la historia para la vida [II INTEMPESTIVA]. España: Biblioteca Nueva.

Nietzsche, F. (1972). Más allá del bien y del mal. España: Alianza. 


\section{Resumen}

Este texto muestra que la noción de «historia crítica» de Friedrich Nietzsche puede ser planteada como una ética. Entendemos ética como la expone Michel Foucault en algunas de sus obras. Para este último, la ética es una práctica de la libertad al ser una resistencia al poder. Esa resistencia no consiste en salir del poder, sino en su ejercicio por parte del individuo sobre sí mismo. En este sentido, puede presentarse a la ética como crítica al poder. Pues la crítica consiste justamente en resistirlo, en cambiar de sentido la forma en la que uno es gobernado. Y eso es la historia crítica de Nietzsche, el juicio sobre las nociones metafísicas del propio pasado que afectan la vida. Mediante la crítica pueden compaginarse historia y ética.

Palabras clave: historia, historia crítica, valor, crítica, ejercicio de poder, relaciones de saber, ética, sujeto, libertad.

\section{Abstract}

This text intent to show that Friedrich Nietzsche's concept of 'critical history' may be approached as an ethic. We understand ethic as presented by Michel Foucault in some of his works. For Foucault, ethic is a practice of freedom upon being a resistance to power. This resistance is not breaking away of power, but its exercise from the individual upon oneself. Accordingly, ethic may be presented as a criticism of power. Thus, the critic consists precisely in resisting it, in changing the direction of the way in which one is governed. And this is the critical history of Nietzsche, the judgement concerning the metaphysical notions of the own past which affect life. Through critic history and ethic can be combined. 
Key words: history, critical history, value, critic, exercise of power, links of knowledge, ethic, subject, freedom. 